\title{
Annealing effects on the photoluminescence of terbium doped zinc oxide films
}

\author{
A. Ziani ${ }^{\text {a,* }}$, C. Davesnne ${ }^{\text {a }}$, C. Labbé ${ }^{\text {a }}$, J. Cardin ${ }^{\text {a }}$, P. Marie ${ }^{\text {a }}$, C. Frilay ${ }^{\text {a }}$, S. Boudin ${ }^{\text {b }}$, X. Portier ${ }^{\text {a }}$ \\ a CIMAP, CEA/UMR CNRS 6252/ENSICAEN/Université de Caen Basse Normandie 6, Boulevard Maréchal Juin, 14050 Caen, France \\ b CRISMAT, UMR CNRS 6508/ENSICAEN/Université de Caen Basse Normandie 6, Boulevard Maréchal Juin, 14050 Caen, France
}

Keywords:

Rare earth doping

$\mathrm{Tb}: \mathrm{ZnO}$

Films

RF magnetron sputtering

Photoluminescence

Annealing treatment

\begin{abstract}
A B S T R A C T
Terbium doped zinc oxide ( $\mathrm{Tb}: \mathrm{ZnO}$ ) films were deposited by radio frequency magnetron sputtering on (100) single-crystalline silicon substrates at low temperature $\left(\mathrm{T}_{\mathrm{S}}=100{ }^{\circ} \mathrm{C}\right)$. In this work, structural changes, optical properties and the associated photoluminescence (PL) responses are analyzed upon the annealing treatments. Post-annealing treatments from annealing temperature $\mathrm{T}_{\mathrm{a}}=400{ }^{\circ} \mathrm{C}$ up to $1000{ }^{\circ} \mathrm{C}$ by steps of $100{ }^{\circ} \mathrm{C}$ were performed. Chemical analyses by energy dispersive X-ray spectrometry measurements showed a constant dopant concentration of 3 at.\%. Up to $600{ }^{\circ} \mathrm{C}$, the band gaps $\left(\mathrm{E}_{\mathrm{g}}\right)$ decreased with $\mathrm{T}_{\mathrm{a}}$ from 3.44 down to $3.37 \mathrm{eV}$. Above $600{ }^{\circ} \mathrm{C}$, the band gap raised from 3.37 up to $3.42 \mathrm{eV}$ (for $900{ }^{\circ} \mathrm{C}$ ). Depending on $\mathrm{T}_{\mathrm{a}}$, a bi-axial stress was found varying from a compressive value of $-0.21 \mathrm{GPa}\left(400{ }^{\circ} \mathrm{C}\right)$ down to a tensile value of $0.05 \mathrm{GPa}\left(1000{ }^{\circ} \mathrm{C}\right)$. PL mechanisms of the $\mathrm{Tb}: \mathrm{ZnO}$ film are then discussed.
\end{abstract}

\section{Introduction}

Among the various materials used in the microelectronic industry, zinc oxide $(\mathrm{ZnO})$ is a promising material due to its high electron mobility, good thermal conductivity, wide and direct band gap and large exciton binding energy. This material is already used in many applications, including transparent thin-film transistors, photodetectors, lightemitting diodes (LED) and laser diodes. Furthermore, it is a cheap and environmentally safe material. In the field of optoelectronic industry, $\mathrm{ZnO}$ thin films are the object of numerous studies [1,2]. ZnO, electrically or optically excited, emits in the UV spectral range due to its band gap $(3.36 \mathrm{eV})$ as well as in the blue/green spectral region originating from intrinsic defects in the matrix. Doped $\mathrm{ZnO}$ with rare earth elements (RE:ZnO) can also emit in the visible spectral range. For instance, a red emission is observed with Europium $\left(\mathrm{Eu}^{3+}\right)$ doping $[3,4]$ and a green one is achieved by Terbium $\left(\mathrm{Tb}^{3+}\right)$ doping [3]. Based on the contribution of intrinsic defects and RE emissions created in the $\mathrm{ZnO}$ matrix, white light emission can be obtained. The ultimate goal is to demonstrate the possibility of a monolithic LED based on RE:ZnO materials.

$\mathrm{ZnO}$ films are materials used for various applications [5], but there are only a few studies focused on $\mathrm{Tb}$ doping of $\mathrm{ZnO}$ [6,7]. Most of the time, $\mathrm{ZnO}$ doping is performed with group III elements such as Bore

\footnotetext{
* Corresponding author. Tel.: +332314526 61; fax: + 33231452660 . E-mail address: ahmed.ziani@ensicaen.fr (A. Ziani).
}

(B), Gallium (Ga), Indium (In) or Aluminum (Al) [8], leading to an improvement of its electrical conductivity. To a lesser extent, rare earth doping is also found to improve the electrical conductivity of $\mathrm{ZnO}$. Fang et al. [6], who worked on the growth of $\mathrm{ZnO}$ thin films by reactive radiofrequency magnetron sputtering (RMS) with a Tb concentration of 4.1 at.\%, found that the electrical resistivity decreases from $9.4 \cdot 10^{-3} \Omega \cdot \mathrm{cm}$ for undoped films down to $9.3 \cdot 10^{-4} \Omega \cdot \mathrm{cm}$ for Tb doped films and keeping a good optical transparency. Beyond this doping level and similarly to the case of group III dopants, transport properties of $\mathrm{ZnO}$ are deteriorated. As far as optical properties are concerned, the control of different rare earth doping concentrations provides an original way to obtain a monitored spectral distribution of the total luminescence. Other papers deal with the effect of various annealing treatments on the improvement of photoluminescence (PL) and structural properties of the films. Teng et al. [7] showed an increasing $\mathrm{PL}$ intensity of $\mathrm{ZnO}$ defects (green emission) in $\mathrm{Tb}: \mathrm{ZnO}$ thin films grown by RMS as a function of annealing temperature $\left(T_{a}\right)$. Otherwise, other works dealing with $\mathrm{Tb}$ doping in $\mathrm{ZnO}$ powders [9], $\mathrm{ZnO}$ thin films synthesized by dip coating [10], electrodeposition [11] or spray pyrolysis [12] are also reported in literature. Similar studies of Tb:ZnO films doped by Tb implantation are also found in previous works [13]. All these works show an improvement of the PL emission intensity related to the optical transitions of $\mathrm{Tb}^{3+}$ ions (green emission). In our study, we focus on Tb:ZnO films grown by RMS method and submitted to various annealing treatments. In the following, we emphasize on the resulting structural, optical and PL properties of Tb:ZnO films, and the PL excitation/emission mechanisms are discussed. 


\section{Experimental details}

Tb:ZnO films were grown by RMS using a pure $\mathrm{ZnO}$ target. Doping was obtained by placing ten terbium oxide $\left(\mathrm{Tb}_{4} \mathrm{O}_{7}\right)$ calibrated pellets on the surface of the $\mathrm{ZnO}$ target. This number of pellets corresponded to a given surface ratio of the target and thus to a given concentration of the dopant in the film. Films were grown on (100) silicon ( $\mathrm{Si}$ ) substrates whose temperature was fixed at $100{ }^{\circ} \mathrm{C}$. The total pressure $\left(\mathrm{P}_{\mathrm{T}}\right)$ and the RF power to target $\left(\mathrm{P}_{\mathrm{RF}}\right)$ were kept equal to $1.5 \mathrm{~Pa}$ and $1.91 \mathrm{~W} \cdot \mathrm{cm}^{-2}$, respectively. Using these parameters, the growth rate was found to be about $9 \mathrm{~nm} \cdot \mathrm{min}^{-1}$. All post-annealing treatments were carried out during $1 \mathrm{~h}$ under continuous nitrogen $\left(\mathrm{N}_{2}\right)$ flow at temperatures $\left(\mathrm{T}_{\mathrm{a}}\right)$ ranging from $400{ }^{\circ} \mathrm{C}$ up to $1000{ }^{\circ} \mathrm{C}$ and varied by step of $100{ }^{\circ} \mathrm{C}$.

Surface morphology and chemical analysis observation was performed using a Jeol JSM 6400 scanning electron microscopy (SEM) with classical tungsten filament and a voltage of $12 \mathrm{kV}$. Coupled Oxford Inca Energy coupled Energy Dispersive X ray Spectrometry (EDXS) was used to determine the dopant concentration. X-ray diffraction (XRD) diagrams were recorded using the Bragg-Brentano $\theta-2 \theta$ configuration, on a Philips Xpert NPD Pro diffractometer ( $\mathrm{Cu} \mathrm{K} \alpha_{1}$ radiation), with a $0.005^{\circ}$ angular step size and with a counting time of 4 s per step. Transmission electron microscopy (TEM) observations were performed using a 2010 FEG JEOL microscope operated at $200 \mathrm{kV}$.

Thickness and refractive index $(\mathrm{n}+\mathrm{ik})$ of the films were determined from spectroscopic ellipsometry technique. Measurements were collected by scanning in the 1.5-4.5 eV range by using a JobinYvon Ellipsometer (UVISEL). The energy band gap $\left(E_{g}\right)$ was calculated using the Tauc formalism [14]. We plotted absorption $\alpha^{2}$ as a function of energy considering the linear region of the plot down to zero loss value and found the $E_{g}$ value with an error of about $0.01 \mathrm{eV}$.

The photoluminescence (PL) emission and PL excitation (PLE) measurements were collected by a Jobin-Yvon Fluorolog Spectrofluorometer with a $450 \mathrm{~W}$ Xenon lamp as source of excitation.

\section{Results and discussion}

In this paper, we discuss the annealing temperature effect on the structural and PL properties of Tb:ZnO films. This requires structural and optical characterizations for various films submitted to various annealing treatments. The corresponding PL responses are analyzed and compared to those of an as grown Tb:ZnO film grown in the same sputtering kit. For this purpose, we have grown $1.1 \mu \mathrm{m}$ thick films, namely: Tb:ZnO-1 corresponds to the as-grown film and $\mathrm{Tb}: \mathrm{ZnO}-(\mathrm{x})$ with $\mathrm{x}$ ranging from 2 to 8 correspond to films annealed at temperatures ranging from $400{ }^{\circ} \mathrm{C}$ up to $1000^{\circ} \mathrm{C}$ by steps of $100{ }^{\circ} \mathrm{C}$. EDXS measurements (not shown) indicate that the $\mathrm{Tb}$ atomic percentage in all $\mathrm{ZnO}$ doped films is found almost constant at about 3 at.\%.

Fig. 1 shows a series of XRD diagrams for the as-grown and annealed films. We observe a preferred growth orientation of the $\mathrm{Tb}: \mathrm{ZnO}$ films following the c-axis (00L) denoting a texture of the films. This feature increases with $T_{a}$. Furthermore, one can notice a shift of the (002) peak position from $34.11^{\circ}$ to $34.53^{\circ}$ with $\mathrm{T}_{\mathrm{a}}$. We remind that the expected bulk $\mathrm{ZnO}(002)$ position is $34.42^{\circ}$. Below $\mathrm{T}_{\mathrm{a}}=800^{\circ} \mathrm{C}$, we see a peak broadening of the full width half maximum (FWHM) varying from $0.26^{\circ}$ to $0.46^{\circ}$. For higher $T_{a}$ values, FWHM decreases down to $0.22^{\circ}$ and new peaks related to a new phase are observed in the $\left[28^{\circ}-\right.$ $32^{\circ}$ ] range. This new phase could be attributed to a $\mathrm{Zn}_{\mathrm{x}} \mathrm{Si}_{1}{ }_{-\mathrm{x}} \mathrm{O}$ phase originating from an Si diffusion across the film/substrate interface.

Fig. 2a and c shows bright field TEM images of the doped films annealed at $600{ }^{\circ} \mathrm{C}$ and $900{ }^{\circ} \mathrm{C}$, respectively. Both images reveal a perpendicular columnar growth of the films. The selected area electron diffraction (SAED) patterns shown in Fig. 2b and d confirm a strong (00L) texture. Upon annealing treatment at $900{ }^{\circ} \mathrm{C}$ (Fig. 2c), a thin layer of about $50 \mathrm{~nm}$ thick is formed at the film/substrate interface. Interpreting the XRD data, this layer may correspond to the $\mathrm{Zn}_{\mathrm{x}} \mathrm{Si}_{1}-{ }_{\mathrm{x}} \mathrm{O}_{3}$ phase. The

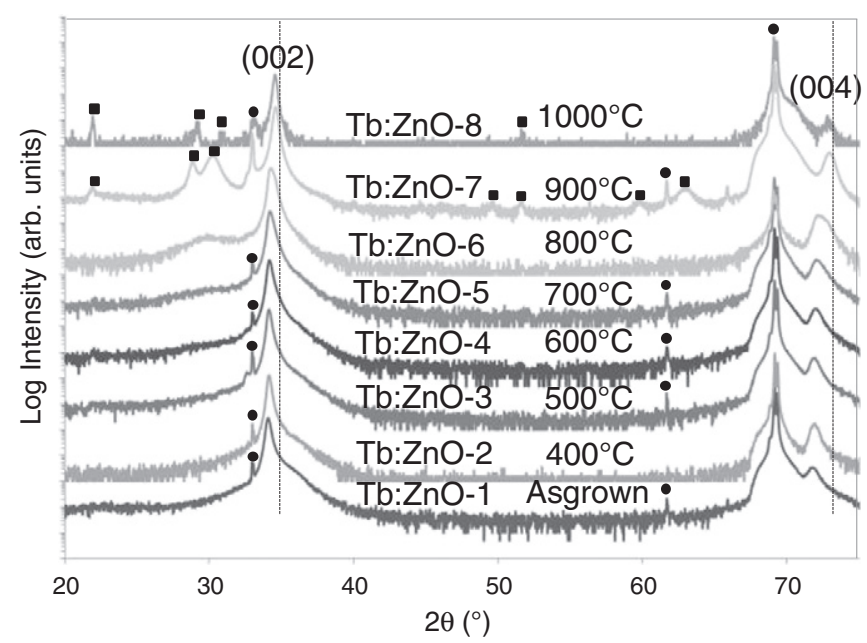

Fig. 1. X-ray diffraction diagrams of as grown Tb:ZnO-1 and annealed thin films from 400 to $1000{ }^{\circ} \mathrm{C}$ ( $\mathrm{Tb}: \mathrm{ZnO}-2$ to $\left.\mathrm{Tb}: \mathrm{ZnO}-8\right)$. The peaks labeled as (-) refer to the Si substrate and the peaks labeled as $(\boldsymbol{\square})$ refer to the $\mathrm{Zn}_{\mathrm{x}} \mathrm{Si}_{1}{ }_{\mathrm{x}} \mathrm{O}_{3}$ phase.

corresponding SAED pattern confirms this new phase by the appearance of two new spots (rings in Fig. 2d). To estimate the grain size, called $\mathrm{D}$, which can be compared to the mean column diameter in $\mathrm{ZnO}$ matrix seen in Fig. 2a and c, we used the Scherrer's formula:

$\mathrm{D}=\frac{0.9 \lambda}{\beta \cdot \cos \theta}$

with $\beta$, the peak width at half height expressed in radians and $\theta$, the diffraction peak position observed.

$\mathrm{ZnO}$ has an hexagonal structure and its $\mathrm{d}_{\mathrm{hkl}}$ spacing is expressed as follows:

$\mathrm{d}_{\mathrm{hkl}}=\frac{\lambda}{\sin \theta}=\frac{a}{\sqrt{\frac{4}{3}\left(\mathrm{~h}^{2}+\mathrm{k}^{2}+\mathrm{hk}\right)+\mathrm{l}^{2} \frac{a^{2}}{\mathrm{c}^{2}}}}$

In the case of (002) orientation, the relationship becomes $\mathrm{c}=2 \mathrm{~d}_{\mathrm{hkl}}=$ $2 \frac{\lambda}{\sin \theta}$.

When $T_{a}$ changes, a shift of the (002) peak is observed. As a result, the $c$ values are deduced and a comparison to the theoretical one $\left(c_{0}=5.206 \AA\right.$ in the JCPDS sheet No. 5-664) provides information on the state of stress for the deposited layers. Indeed, taking $c_{0}$ as a reference for unconstrained $\mathrm{ZnO}$ films, and c for constrained ones, we can calculate strain in the films from the equation:

$\varepsilon=\frac{\mathrm{c}-\mathrm{c}_{0}}{\mathrm{c}_{0}} * 100(\%)$.

Then, we deduce the bi-axial stress in the films from the equation that takes into account the elastic constants of $\mathrm{ZnO}$ [15]:

$\sigma=-232.8 \cdot 10^{-9} * \varepsilon(\mathrm{Pa})$.

Smooth surfaces are obtained for all the films. By contrast, the film annealed at the highest $\mathrm{T}_{\mathrm{a}}$ values ( $\left.\mathrm{Tb}: \mathrm{ZnO}-8\right)$ is dramatically affected. An important roughness is observed at its surface. Furthermore, the film/substrate interface is not stable mechanically. It's comparable to a sintered powder deposited on Si substrate.

Fig. 3 depicts grain size as well as bi-axial stress versus $T_{a}$. The major effect is a decrease of grain size from $32 \mathrm{~nm}$ down to $19.5 \mathrm{~nm}$ for $\mathrm{T}_{a}$ varying from room temperature up to $800{ }^{\circ} \mathrm{C}$. Above $800{ }^{\circ} \mathrm{C}$, we notice an important increase of grain size. A stress relaxation from $-0.18 \mathrm{GPa}$ 

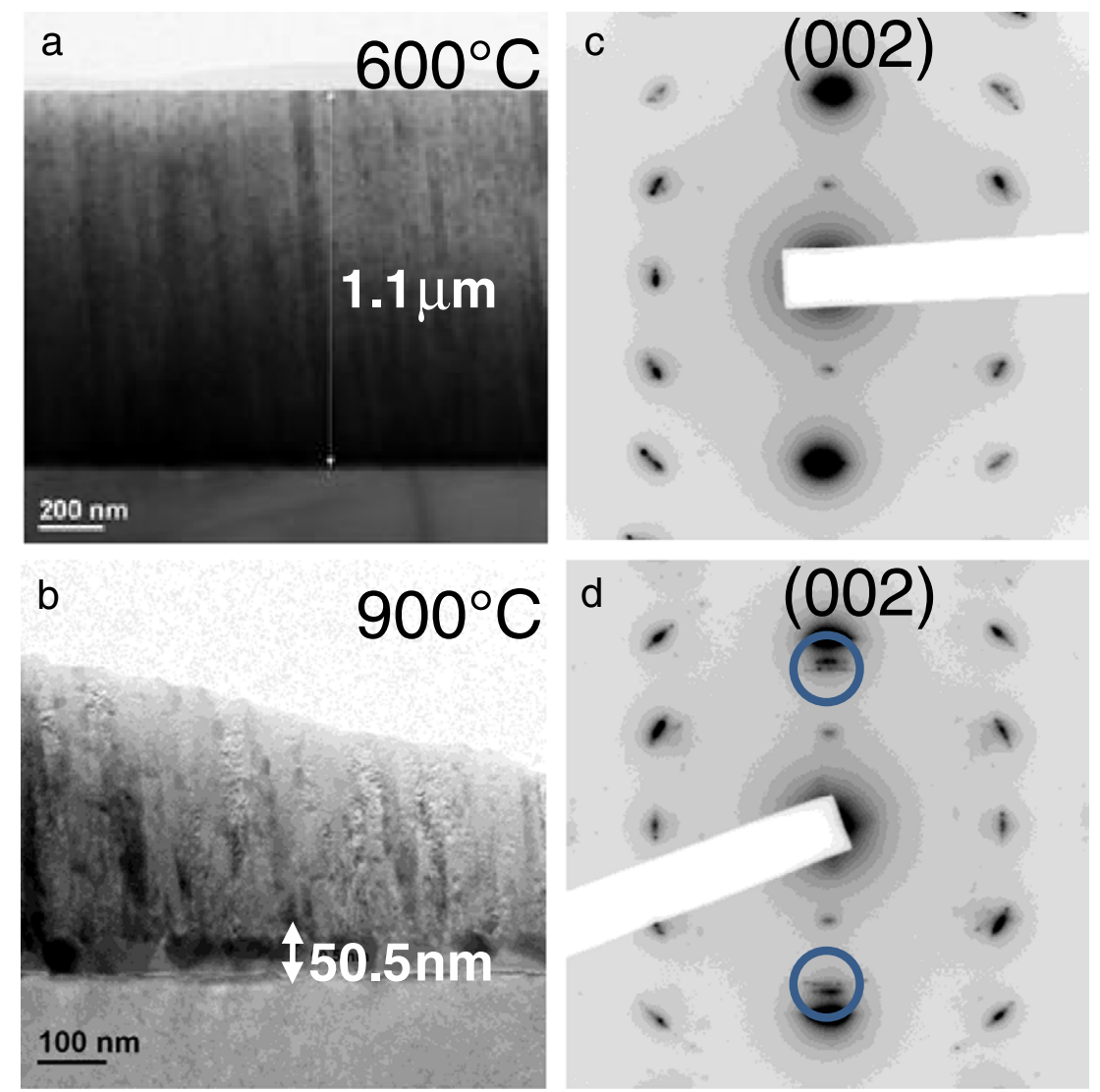

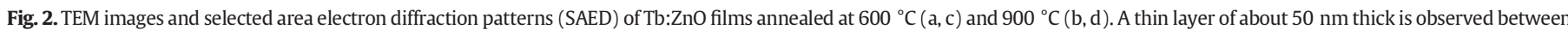
the Si substrate and the film upon the $900{ }^{\circ} \mathrm{C}$ annealing treatment.

down to $0.05 \mathrm{GPa}$ is also observed in the films. These effects are well known and reported in many studies on annealing effects of such films [16,17]. A transition is observed from a compressive to a tensile stress for temperatures higher than $800{ }^{\circ} \mathrm{C}$. This transition could be explained by the appearance of the new phase at the film/substrate interface, which changes the strain configuration at the interface. The characteristics of the films are given in Table 1.

Regarding the optical characterizations, we see that the most visible effect of the annealing treatments is a gradual increase of the refractive index $\mathrm{n}$ for $\mathrm{T}_{\mathrm{a}}$ values up to $600{ }^{\circ} \mathrm{C}$ followed by a collapse at $900{ }^{\circ} \mathrm{C}$ (Fig. 4a). Below $600{ }^{\circ} \mathrm{C}$, we observe a rise from 2.42 up to 2.53 (for an energy value of $3 \mathrm{eV}$ ). Usually, an increase of $n$ values indicates a higher material density [18], a higher degree of crystallization or a better distribution of the dopants in the matrix as observed in our case. The band

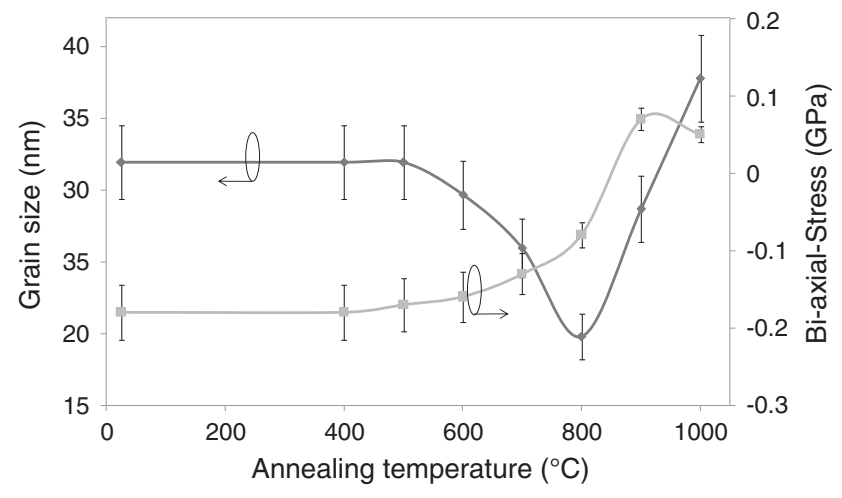

Fig. 3. Grain size and bi-axial stress for different annealing temperatures. gap follows an opposite trend: it decreases from 3.45 (room temperature) down to $3.37 \mathrm{eV}$ for $600{ }^{\circ} \mathrm{C}$ and it rises up to $3.42 \mathrm{eV}$ for $900{ }^{\circ} \mathrm{C}$ (Fig. 4b). In the case of $\mathrm{Zn}_{1-{ }_{x}} \mathrm{Mg}_{\mathrm{x}} \mathrm{O}$ nanocrystals [19], it has been shown that higher $\mathrm{Mg}$ concentration may result in a rising grain size from 10 to $12 \mathrm{~nm}$ and in a decrease of the c ZnO lattice parameter resulting in a band gap increase. Li-Bin et al. [20] found that, for a compressive stress following the $\mathrm{c}$ axis, the conduction band moves to higher energy levels leading to higher band gap in $\mathrm{Zn}_{0.75} \mathrm{Mg}_{0.25} \mathrm{O}$. Li et al. [21] also showed a linear dependency of ZnO band gap energy with respect to compressive bi-axial stress. In those studies, the tensile bi-axial stress of $\mathrm{ZnO}$ thin films deposited on quartz and annealed from 240 to $800{ }^{\circ} \mathrm{C}$ was measured. They found a concomitant increase of biaxial stress from 1.45 to $2.01 \mathrm{GPa}$ and of band gap energy with annealing temperature. In our case, above $600{ }^{\circ} \mathrm{C}$, we obtain an opposite trend of the evolutions of refractive index and band gap with $\mathrm{T}_{\mathrm{a}}$. This may correspond to the beginning of a coarsening behavior at $800{ }^{\circ} \mathrm{C}$ dominated by a diffusion mechanism of $\mathrm{V}_{\mathrm{O}}$ and $\mathrm{Zn}_{\mathrm{i}}$ in the film leading to the formation of a new phase at the interface [22].

Fig. 5a and b displays PL and PLE spectra, respectively for the various $\mathrm{T}_{\mathrm{a}}$ values. As shown in Fig. 5a, up to $600{ }^{\circ} \mathrm{C}$, we observe an increase of the PL emission of ${ }^{5} \mathrm{D}_{4} \rightarrow{ }^{7} \mathrm{~F}_{\mathrm{i}}(\mathrm{i}=6,5,4,3)$ transitions and especially the ${ }^{5} \mathrm{D}_{4} \rightarrow{ }^{7} \mathrm{~F}_{5}(545 \mathrm{~nm})$ one. This maximum intensity observed for $600{ }^{\circ} \mathrm{C}$ is coherent with the lowest band gap value of the matrix (maximum absorption) and also with the highest $\mathrm{n}$ value (consistent with an homogeneous distribution of the Tb ions in the matrix). Beyond $600{ }^{\circ} \mathrm{C}$, the intensities of these transitions diminish drastically until complete disappearance for $\mathrm{T}_{\mathrm{a}}=800{ }^{\circ} \mathrm{C}$. Up to $800{ }^{\circ} \mathrm{C}$, annealing of $\mathrm{Tb}: \mathrm{ZnO}$ films have led to a better crystallinity of the films (higher degree of texturing). It allowed a biaxial stress relaxation and then a better absorption of $\mathrm{ZnO}$ matrix. A better carrier distribution permits a better $\mathrm{Tb}$ optical activation. For excitation energies above the band gap of $\mathrm{Tb}$ : 
Table 1

Characteristics of the annealed Tb:ZnO thin films ( $\mathrm{T}_{\mathrm{a}}=400$ to $\left.1000{ }^{\circ} \mathrm{C}\right)$.

\begin{tabular}{|c|c|c|c|c|c|c|c|c|c|c|c|}
\hline Sample & $\begin{array}{l}\text { Annealing } \\
\text { temperature } \\
\left({ }^{\circ} \mathrm{C}\right)\end{array}$ & $\begin{array}{l}\text { FWHM } \\
\left({ }^{\circ}\right)\end{array}$ & $\begin{array}{l}2 \theta \\
\left({ }^{\circ}\right)\end{array}$ & $\begin{array}{l}\text { Grain size } \\
(\mathrm{nm})\end{array}$ & $c(\AA)$ & $\begin{array}{l}\text { Strain } \\
(\%)\end{array}$ & $\begin{array}{l}\text { Bi-axial stress } \\
(\mathrm{GPa})\end{array}$ & $\begin{array}{l}\text { PL intensity at } \\
545 \mathrm{~nm} \\
\text { ( } \mathrm{Nb} \text { of counts) }\end{array}$ & $\begin{array}{l}\text { PL intensity at } \\
385 \mathrm{~nm} \\
\text { ( } \mathrm{Nb} \text { of counts) }\end{array}$ & $\begin{array}{l}\text { Band gap } \\
(\mathrm{eV})\end{array}$ & $\begin{array}{l}\text { Refractive } \\
\text { index } \\
(\text { at } 3 \mathrm{eV} \text { ) }\end{array}$ \\
\hline Tb:ZnO-1 & 25 & 0.26 & 34.11 & $31.96 \pm 2.48$ & 5.253 & -0.91 & $(-) 0.18 \pm 0.02$ & 480 & 0 & $3.44 \pm 0.01$ & $2.42 \pm 0.05$ \\
\hline $\mathrm{Tb}: \mathrm{ZnO}-2$ & 400 & 0.26 & 34.12 & $31.96 \pm 2.47$ & 5.251 & -0.88 & $(-) 0.18 \pm 0.02$ & 1640 & 0 & $3.39 \pm 0.01$ & $2.43 \pm 0.05$ \\
\hline $\mathrm{Tb}: \mathrm{ZnO}-3$ & 500 & 0.26 & 34.13 & $31.96 \pm 2.47$ & 5.25 & -0.85 & $(-) 0.17 \pm 0.02$ & 2830 & 0 & $3.38 \pm 0.01$ & $2.45 \pm 0.05$ \\
\hline $\mathrm{Tb}: \mathrm{ZnO}-4$ & 600 & 0.28 & 34.15 & $29.68 \pm 2.14$ & 5.247 & -0.79 & $(-) 0.16 \pm 0.02$ & 4360 & 0 & $3.37 \pm 0.01$ & $2.53 \pm 0.05$ \\
\hline Tb:ZnO-5 & 700 & 0.32 & 34.19 & $25.97 \pm 1.64$ & 5.241 & -0.68 & $(-) 0.13 \pm 0.02$ & 1830 & 0 & $3.39 \pm 0.01$ & $2.39 \pm 0.05$ \\
\hline $\mathrm{Tb}: \mathrm{ZnO}-6$ & 800 & 0.42 & 34.27 & $19.79 \pm 0.95$ & 5.229 & -0.45 & $(-) 0.08 \pm 0.02$ & 0 & 1060 & $3.41 \pm 0.01$ & $2.35 \pm 0.05$ \\
\hline $\mathrm{Tb}: \mathrm{ZnO}-7$ & 900 & 0.29 & 34.58 & $28.69 \pm 1.99$ & 5.184 & 0.42 & $0.07 \pm 0.02$ & 0 & 10,800 & $3.42 \pm 0.01$ & $2.25 \pm 0.05$ \\
\hline $\mathrm{Tb}: \mathrm{ZnO}-8$ & 1000 & 0.22 & 34.53 & $37.82 \pm 3.46$ & 5.191 & 0.28 & $0.05 \pm 0.02$ & 0 & 138,000 & / & / \\
\hline
\end{tabular}

$\mathrm{ZnO}$, we see a Tb optical activation in the matrix. We showed an optimal $\mathrm{Tb}$ activation in $\mathrm{ZnO}$ matrix at $600{ }^{\circ} \mathrm{C}$. For temperatures higher than $800{ }^{\circ} \mathrm{C}\left(800-1000{ }^{\circ} \mathrm{C}\right)$, the emergence of a PL band at $387 \mathrm{~nm}$ is visible and becomes more intense when $\mathrm{T}_{\mathrm{a}}$ is raised. This PL peak is clearly attributed to the conduction to valence band transition in $\mathrm{ZnO}$ matrix [7]. The $\mathrm{Tb}$ PL extinction is progressively decreasing from $600{ }^{\circ} \mathrm{C}$ up to $800{ }^{\circ} \mathrm{C}$, temperature from which the signal has completely disappeared. This is most probably due to a "quenching" effect which presumably results from the segregation of $\mathrm{Tb}$ ions upon annealing treatment at high temperatures. In the literature, some works on undoped $\mathrm{ZnO}$ films showed a degradation of the PL beyond $800{ }^{\circ} \mathrm{C}$ and demonstrated also the appearance of a large band around $500 \mathrm{~nm}$ due to an increase of defect density. This PL defect states related do not appear in our spectra. For temperatures higher than $800{ }^{\circ} \mathrm{C}$, the diffusion of chemical species in the matrix attenuates the texturing effect and subsequently disturbs

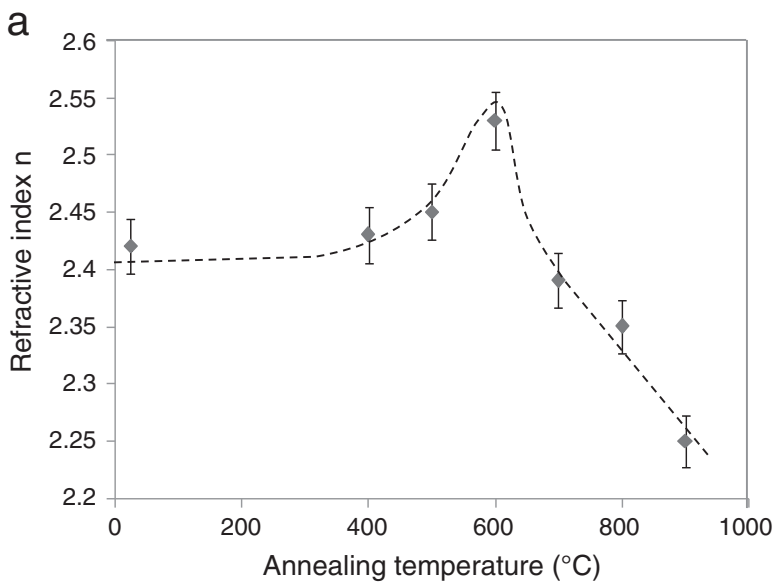

b

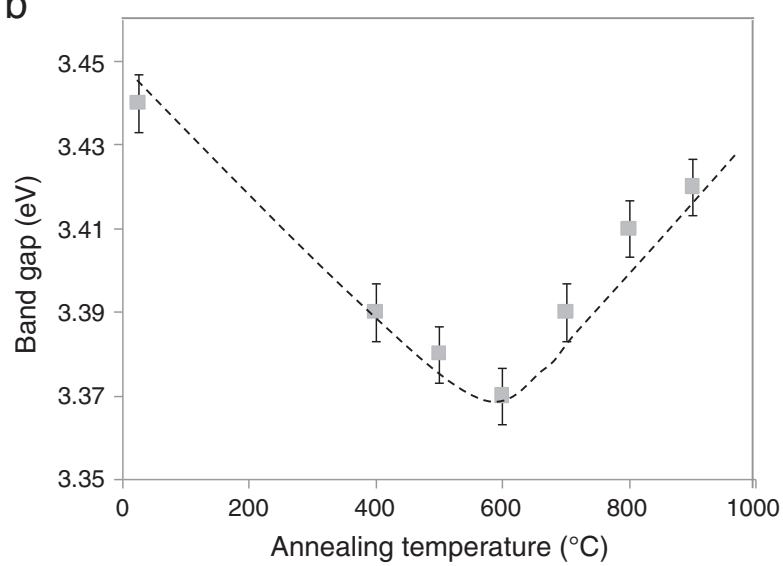

Fig. 4. (a) Refractive indices of $\mathrm{Tb}: \mathrm{ZnO}$ films at $\mathrm{E}=3 \mathrm{eV}$ annealed at different temperatures from 400 to $1000{ }^{\circ} \mathrm{C}$, (b) band gap versus annealing temperature. the carriers' distribution. To investigate these phenomena in more details with temperature, we performed PLE spectra with respect to $T_{a}$ for $\mathrm{Tb}: \mathrm{ZnO}$ (as-grown, $600{ }^{\circ} \mathrm{C}$ and $900{ }^{\circ} \mathrm{C}$ ) and undoped $\mathrm{ZnO}$ (annealed at $600{ }^{\circ} \mathrm{C}$ ) films. Regarding the PLE measurements (Fig. 5b) with a detection wavelength at $490 \mathrm{~nm}\left({ }^{5} \mathrm{D}_{4} \rightarrow{ }^{7} \mathrm{~F}_{6}\right)$ for $\mathrm{Tb}^{3+}$, we observe for undoped $\mathrm{ZnO}$ annealed at $600{ }^{\circ} \mathrm{C}$ as well as for as grown and annealed at $900{ }^{\circ} \mathrm{C} \mathrm{Tb}: \mathrm{ZnO}$ films two broad peaks centered at 282 and $380 \mathrm{~nm}$. These two levels correspond to $4 \mathrm{f} \rightarrow 5 \mathrm{~d}$ transitions of $\mathrm{Tb}^{3+}$ ions and to $\mathrm{ZnO}$ host matrix, respectively [23-25]. At $900{ }^{\circ} \mathrm{C}$, we see a PLE signal almost similar to that observed for undoped $\mathrm{ZnO}$ films, meaning that $\mathrm{Tb}$ ions are not active. For the as grown Tb:ZnO films, the two levels are weak and demonstrate that an annealing treatment is necessary to activate the dopants. For $\mathrm{T}_{\mathrm{a}}=600{ }^{\circ} \mathrm{C}$, we note an intense response of the 4f $\rightarrow 5 \mathrm{~d}$ transition indicating an effective Tb activation due to the defect passivation. However, the peak at $380 \mathrm{~nm}$ has disappeared suggesting that the $\mathrm{ZnO}$ matrix is not contributing to the Tb excitation. Regarding the Tb excitation/emission mechanisms below $600{ }^{\circ} \mathrm{C}$, we refer to two ways of Tb emissions. Several models of Tb emission/excitation mechanisms in $\mathrm{ZnO}$ are proposed in the literature depending on the scale of ZnO material (particle size, film structures) [9-11,26-28]. In these studies, the emission process takes place via an energy transfer occurring from the host matrix to the $\mathrm{Tb}^{3+}$ ions, from the conduction band directly or through matrix defects. This process is more relevant for $\mathrm{Tb}$ ions well incorporated in the crystalline structure of the $\mathrm{ZnO}$ host matrix. However, these mechanisms in Tb:ZnO films are still a matter of debate. Another process is generated directly through $\mathrm{Tb}^{3+}$ ions emitting via its energy levels. This is the case for matrices with a large band gap requiring high excitation energy $[29,30]$.

To investigate the energy transfer mechanism in our doped annealed films, we report, in Fig. 6a, PL spectra of the Tb:ZnO film annealed at $600{ }^{\circ} \mathrm{C}$ at different excitation wavelengths $(415,330,350$ and $282 \mathrm{~nm}$ ). (i) The $415 \mathrm{~nm}$ wavelength is nonresonant with the RE dopant. We detect a broad PL band in the $390 \mathrm{~nm}-650 \mathrm{~nm}$ spectral range. This emission is usually attributed to zinc and/or oxygen vacancies and interstices in $\mathrm{ZnO}$ matrix [31]. In order to know whether these emissions [390 nm-650 nm] are originating from $\mathrm{ZnO}$ host defects or the ${ }^{5} \mathrm{D}_{3} \rightarrow{ }^{7} \mathrm{~F}_{\mathrm{i}}$ Tb transitions [30,32,33], we compared a Tb:ZnO film annealed at $600{ }^{\circ} \mathrm{C}$ to a very thick ( $4 \mu \mathrm{m}$ ) undoped $\mathrm{ZnO}$ film (Fig. $6 \mathrm{~b}$ ). For an excitation at $330 \mathrm{~nm}$, we observed a superposition of the PL contribution from the defects of undoped $\mathrm{ZnO}$ and that of $\mathrm{Tb}: \mathrm{ZnO}$ film. This result proves that the 395,415 438, 470, and $508 \mathrm{~nm}$ PL peaks come from the $\mathrm{ZnO}$ defects [31]. Furthermore, the PL emission peaks are not interference effect and we do not observe any transfer from the defects towards the dopants. (ii) At $385 \mathrm{~nm}$ in Fig. 6a, below the conduction band of $\mathrm{ZnO}$, we still detect the defect signature but more intensely. (iii) At $350 \mathrm{~nm}$, above the $\mathrm{ZnO}$ band gap but non-resonant with the Tb dopant, we detect once again the defect signature but we also see the presence of ${ }^{5} \mathrm{D}_{4} \rightarrow{ }^{7} \mathrm{~F}_{\mathrm{i}}(\mathrm{i}=6,5,4,3)$ peaks related to $\mathrm{Tb}$ energy levels. (iv) When the sample is excited at $282 \mathrm{~nm}$, Tb ions and defects in $\mathrm{ZnO}$ matrix are both emitting due to a better distribution of the free carriers in ZnO host matrix. Indeed, intense PL signals are observed due to a direct $\mathrm{Tb}$ excitation. 
a

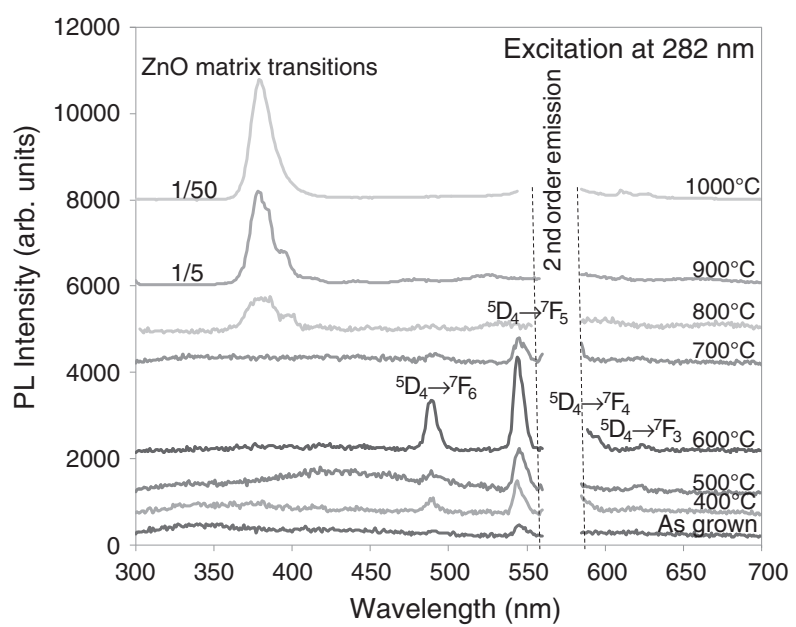

b

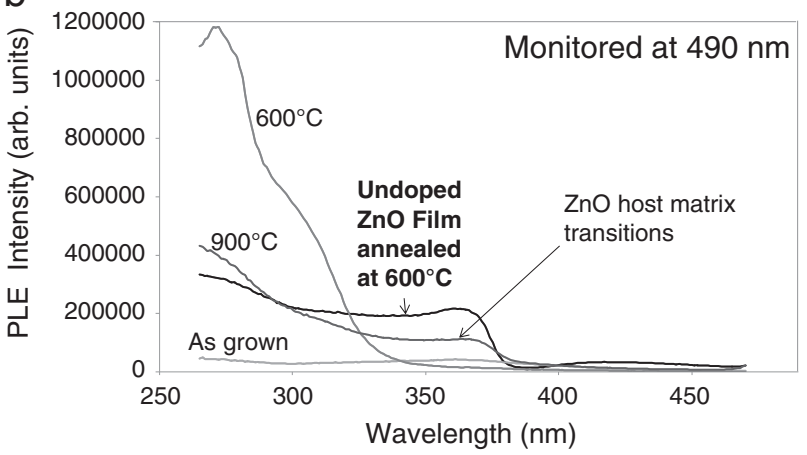

Fig. 5. (a) PL spectra of the annealed $\mathrm{Tb}: \mathrm{ZnO}$ samples with excitation wavelength at $282 \mathrm{~nm}$ and (b) PLE spectra with detection wavelength at $490 \mathrm{~nm}$ of Tb ZnO films as grown, annealed at $600{ }^{\circ} \mathrm{C}$, annealed at $900{ }^{\circ} \mathrm{C}$ and undoped $\mathrm{ZnO}$ film.

\section{Conclusion}

In this work, we analyzed the annealing treatment effect on the photoluminescence properties of $\mathrm{Tb}: \mathrm{ZnO}$ films with a doping rate of 3 at.\%. Thermal annealing up to $600{ }^{\circ} \mathrm{C}$ resulted in an optimum emission of the $\mathrm{Tb} \mathrm{D}_{\text {levels }}$ such as the radiative transitions ${ }^{5} \mathrm{D}_{4} \rightarrow{ }^{7} \mathrm{~F}_{\mathrm{i}}(\mathrm{i}=6,5,4,3)$ and especially the ${ }^{5} \mathrm{D}_{4} \rightarrow{ }^{7} \mathrm{~F}_{5}(545 \mathrm{~nm})$ one. This result suggests that this anneal treatment favors an optimum distribution of the ions in the matrix. Above this temperature, a quenching mechanism was observed until a complete disappearance (from $800{ }^{\circ} \mathrm{C}$ ) of the Tb emission. Beyond $800{ }^{\circ} \mathrm{C}$, we observed a structure deterioration of the $\mathrm{ZnO}$ host matrix due to a diffusion process between the Si substrate and the film as well as an increase of tensile stress of the film. We observed the emergence of radiative $\mathrm{ZnO}$ band gap ( $387 \mathrm{~nm}$ ) transition. This transition increased significantly with annealing temperature until $1000{ }^{\circ} \mathrm{C}$.

Furthermore, the maximum PL intensity of $\mathrm{Tb}$ ions occurred upon annealing at $600{ }^{\circ} \mathrm{C}$. By contrast, the stress evolution analysis showed that a compressive stress was present in the film upon annealing treatment from room temperature up to $800{ }^{\circ} \mathrm{C}$. At this latter temperature, a relaxation of the film was reached. Above this temperature, a tensile stress appeared. We conclude that there is no relationship between the stress state of the film and the Tb emission.

Currently, we are conducting several studies of the doping ratio effect on the PL properties. Time decay measurements will also be carried out for a deeper understanding of the transfer mechanisms in Tb:ZnO film.

\section{Acknowledgments}

This work was supported by CEA ${ }^{2}$ (Commissariat à l'Energie Atomique et aux Energies Alternatives) through the DSM Energies Program.
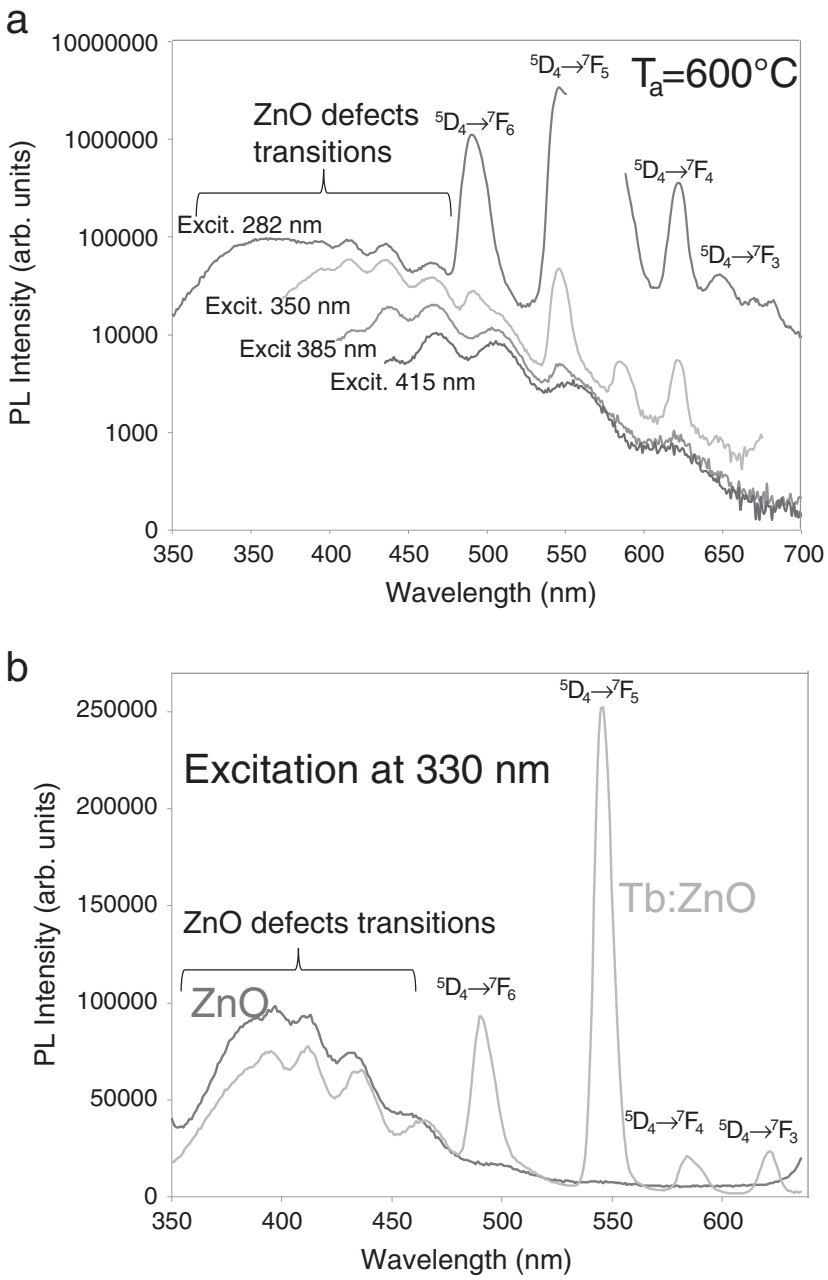

Fig. 6. (a) PL spectra of $\mathrm{Tb}: \mathrm{ZnO}$ annealed at $600{ }^{\circ} \mathrm{C}$ with different excitation between $282 \mathrm{~nm}$ and $415 \mathrm{~nm}$ and (b) comparison between $\mathrm{Tb}: \mathrm{ZnO}$ and a undoped $\mathrm{ZnO}$ films grown with similar conditions with excitation at $330 \mathrm{~nm}$.

\section{References}

[1] U. Ozgur, Y.I. Alivov, C. Liu, A. Teke, M.A. Reshchikov, S. Dogan, V. Avrutin, S.J. Cho, H Morkoc, J. Appl. Phys. 98 (2005) 041301.

[2] D.K. Hawang, M.S. Oh, J.H. Lim, S.J. Park, J. Phys. D: Appl. Phys. 40 (2007) R 387.

[3] N.J. Awang, M. Aziz, A.R.M. Yusoff, Solid State Sci. Technol. 16 (2008) 45.

[4] J. Petersen, C. Brimont, M. Gallart, G. Schmerber, P. Gilliot, C. Ulhaq-Bouillet, J.L. Rehspringer, S. Colis, C. Becker, A. Slaoui, A. Dinia, J. Appl. Phys. 107 (2010) 123522.

[5] A.B. Djurisic, Y.H. Leung, Small 2 (2006) 944.

[6] Z.B. Fang, Y.S. Tang, H.X. Gong, C.M. Zhen, Z.W. He, Y.Y. Wang, Mater. Lett. 59 (2005) 2611.

[7] X.M. Teng, H.T. Fang, S.S. Pan, C. Ye, G.H. Li, J. Appl. Phys. 100 (2006) 053507.

[8] T. Minami, H. Sato, H. Nanto, S. Takata, Jpn. J. Appl. Phys. 24 (1985) L781.

[9] S.M. Liu, F.Q. Liu, Z.G. Wang, Chem. Phys. Lett. 343 (2001) 489.

[10] J. Zhang, H. Feng, W. Hao, T. Wang, Mater. Sci. Eng. A 425 (2006) 346

[11] S. Zhao, L. Wang, L. Yong, Z. Wang, Physica B 405 (2010) 3200.

[12] A. Ortiz, C. Falcony, M. Garcia, A. Sanchez, J. Phys. D. Appl. Phys. 20 (1987) 670.

[13] A. Cetin, R. Kibar, S. Selvi, P.D. Townsend, N. Can, Physica B 404 (2009) 3379.

[14] J. Tauc, R. Grigorovici, A. Vancu, Phys. Status Solidi 15 (1966) 627.

[15] S.Y. Ting, P.J. Chen, H.C. Wang, C.H. Liao, W.M. Chang, Y.P. Hsieh, C.C. Yang, J. Nanomater. 2012 (2012) 6.

[16] F.H. Shan, G.X. Liu, B.C. Shin, W.J. Lee, J. Korean Phys. Soc. 54 (2009) 916.

[17] K.S. Kim, H.W. Kim, N.H. Kim, Physica B 334 (2003) 343.

[18] C. Besleaga, G.E. Stan, A.C. Galca, L. Ion, S. Antohe, Appl. Surf. Sci. 258 (2012) 8819.

[19] M. Ghosh, A.K. Raychaudhuri, J. Appl. Phys. 100 (2006) 034315.

[20] S. Li-Bin, L. Ming-Biao, R. Jun-Yuan, W. Li-Jin, X. Cui-Yan, Chin. Phys. B 18 (2009) 726.

[21] Y.F. Li, B. Yao, Y.M. Lu, Y.Q. Gai, C.X. Cong, Z.Z. Zhang, D.X. Zhao, J.Y. Zhang, B.H. Li, D.Z. Shen, X.W. Fan, Z.K. Tang, J. Appl. Phys. 104 (2008) 083516.

[22] Z.W. Liu, W.J. Fu, M. Liu, J.F. Gu, C.Y. Ma, Q.Y. Zhang, Surf. Coat. Technol. 202 (2008) 5410.

[23] R. Reisfeld, Z. Gur-Arieh, E. Greenberg, Anal. Chim. Acta. 50 (1970) 249.

[24] T. Hoshina, Jpn. J. Appl. Phys. 6 (1967).

[25] C.K. Duan, C.C. Ko, G. Jia, X. Chen, P.A. Tanner, Chem. Phys. Lett. 506 (2011) 179. 
[26] S.M. Liu, F.O. Liu, H.Q. Guo, Z.H. Zhang, A.G. Wang, Phys. Lett. A 271 (2000) 128.

[27] L. Yang, Y. Tang, A. Hu, X. Chen, K. Liang, L. Zhang, Physica B 403 (2008) 2230.

[28] Y.T. An, C. Labbé, M. Morales, P. Marie, F. Gourbilleau, Phys. Status Solidi C 9 (2012) 2207.

[29] A. Podhorodecki, N.V. Gaponenko, M. Banski, T. Kim, J. Misiewicz, ECS Trans. 28 (2010) 81.
[30] A. Podhorodecki, M. Banski, J. Misiewicz, J. Serafinczuk, N.V. Gaponenko, J. Electrochem. Soc. 157 (2010) H628.

[31] A.B. Djurisic, A.M.C. Ng, X.Y. Chen, Prog. Quantum Electron. 34 (2010) 191.

[32] H.X. Zhang, C.H. Kam, Y. Zhou, X.Q. Han, S. Buddhudu, Y.L. Lam, C.Y. Chan, Thin Solid Films 370 (2000) 50.

[33] H. Amekura, A. Eckau, R. Carius, Ch. Buchal, J. Appl. Phys. 84 (1998) 3867. 